This version of the article has been accepted for publication, after peer review but is not the Version of Record and does not reflect post-acceptance improvements, or any corrections. The Version of Record is available online at: http://dx.doi.org/10.1007/s13280-021-01664-1. Use of this Accepted Version is subject to the publisher's Accepted Manuscript terms of use https://www.springernature.com/gp/open-research/policies/accepted- manuscript-terms

\title{
How ecological research on human-dominated ecosystems incorporates agricultural and forestry practices: a literature analysis
}

\section{Authors}

Julien Blanco ${ }^{1,2, *}$, Guillaume Ollivier ${ }^{3}$, Audrey Alignier ${ }^{4}$, Stéphanie Aviron ${ }^{4}$, Clélia Sirami ${ }^{1}$, Éric Kernéïs ${ }^{5}$, Daphné Durant ${ }^{5, \uparrow, ~ R o d o l p h e ~ S a b a t i e r ~}{ }^{3, \pi}$

\section{Author affiliations}

${ }^{1}$ Université de Toulouse, INRAE, UMR DYNAFOR, F-31326, Castanet-Tolosan, France

${ }^{2}$ SENS, IRD, CIRAD, Univ Paul Valery Montpellier 3, Univ Montpellier, Site St Charles, Route de Mende, 34199 Montpellier Cedex 5, France

${ }^{3}$ INRAE, ECODEVELOPPEMENT, F-84914, Avignon, France

${ }^{4}$ INRAE, Institut Agro, ESA, UMR 0980 BAGAP, F-35042, Rennes, France

${ }^{5}$ INRAE, DSLP, F-17450, Saint-Laurent-de-la-Prée, France

` DD and RS contributed equally to this work

* Corresponding author:

Julien Blanco: Email: julien.blanco@,ird.fr / Phone: + 33 (0) 687901110 


\begin{abstract}
Understanding the nexus between practices and ecosystems is a critical challenge for sustainability, but it is unclear how ecological sciences have explored the question. To bring clarification, we conducted an analysis of ecology literature dealing with agricultural and forestry practices (AF practices), scanning a total of 27556 references. Scientometric analyses showed that AF practices were addressed by $5.5 \%$ of ecology literature, and that this proportion increased from $2.5 \%$ to $8.1 \%$ between 1956 and 2017. Content analyses showed that research has mainly focused on monospecific systems in the Global North, predominantly using plotlevel experimental approaches. Temporal monitoring, real-world practices and their social context were poorly investigated. This analysis stresses the need to reinforce research in complex agroecosystems, in particular in non-Western countries. Multilevel and spatiotemporal approaches, as well as participatory research, should also be encouraged to build a social-ecological understanding and formulate more grounded, relevant policy recommendations for sustainability.
\end{abstract}

\title{
Keywords
}

Agriculture; Forestry; Human-nature relationships; Practitioners; Scientometrics; SocialEcological Systems. 


\section{Introduction}

Ecology - as the scientific discipline studying interactions between living beings and their environment - has traditionally focused on pristine, 'natural' ecosystems, scarcely integrating humans in its scope (Barnaud and Lefeuvre 1992; Liu 2001; Lowe et al. 2009; Lopes 2017). However, this traditional vision has been increasingly questioned for two main reasons. The first is the emergence of the environmental crisis due to the development of human populations and their activities, which put a new public focus on the science of ecology (first in the 1930s and generalized since the 1960s; Worster 1994). This has resulted in spirited debates, as well as some discomfort among ecologists, about the credibility and professional responsibility of ecologists as problem-solvers (Kinchy and Kleinman 2003). Secondly, over the decades, conceptual and theoretical shifts have challenged the way ecologists initially considered equilibrium and complex systems, and thus the place of humans in ecosystems (Holling 1973; Madison 1997).

As a result, humans have been progressively integrated within the conceptual framework of ecology (Liu 2001; Lowe et al. 2009). For instance, in the 1960s, the Odum brothers proposed a 'New Ecology' approach, advocating for the development of an applied ecology that aimed at building bridges between natural ecosystems and human systems (Madison 1997). In the 1970s, the field of agroecosystem research emerged (Loucks 1977). During the same period, Holling (1969) conceptualized social-ecological systems (SES) as complex, adaptive systems in which social agents and biophysical elements interact at multiple levels. These different conceptual advances all highlighted the porosity between social and natural systems, challenging the naturalist ontology and contributing to increased collaborations between ecology and social sciences (Ollivier et al. 2018).

Today, humans are recognized as a global force affecting all ecosystems on Earth, and the concept of SES has become central in ecology (Steffen et al. 2007). This integrated understanding of social and ecological dynamics is considered essential to address pressing sustainability challenges and provide effective and actionable solutions to the current environmental crisis. Yet overall integration is still lacking in social-ecological research, in particular with regard to the incorporation of a comprehensive set of social and ecological variables (Guerrero et al. 2018). Furthermore, it remains unclear to what extent the human aspect has been integrated in ecology research - an aspect that is particularly relevant to consider in research on human-dominated ecosystems such as agroecosystems and forestry systems. 
Management practices - defined as concrete, intentional activities executed by actors in order to modify the environment for productive purposes and framed by broad and complex technological, economic, psychological, cognitive, social, institutional and/or cultural factors (Baumgart-Getz et al. 2012; Ollivier et al. 2018; Dessart et al. 2019) - are critical to understand the links between ecological and social dynamics and to foster the sustainable management of human-dominated systems. These practices lie at the interface between social and ecological systems, so they represent a good starting point to investigate the nexus between human agency and managed ecosystems.

The aim of this analysis was to investigate how agricultural and forestry management practices (hereafter referred to as AF practices) have been studied in ecological research on human-dominated ecosystems, addressing four main questions: (i) What is the importance of AF practices in ecology and how has this evolved over time? (ii) To what extent is this topic valued in ecology? (iii) What approaches and methods have been used to investigate AF practices? and (iv) What lessons about this can be drawn from the existing literature? To address these questions, we first assessed the place of AF practices in ecology literature according to journal prestige and changing interest in the topic over time, based on a scientometric analysis. We then examined how AF practices are understood and analyzed in the face of ecological processes and dynamics based on an in-depth qualitative analysis. Finally, we assessed the implication of the results in order to make recommendations for future ecology research.

\section{Materials \& methods}

Our analysis was based on a two-step approach. First, we created a lexical query to extract from the literature all ecology articles dealing with AF practices (hereafter termed 'global corpus'), which we analyzed using scientometric techniques. In the second step, we randomly selected a representative subcorpus of articles that we qualitatively hand-coded based on a content analysis of each article's full text.

\subsection{Identification of the global corpus}

We used the Web of Science Core Collection (WoS, Clarivate Analytics from 1956; Appendix S1. Methods), which is the most authoritative database for scientometrics, 
increasingly used by scholars worldwide (Zhu and Liu 2020) and providing a large set of metadata for quantitative analyses (citations, authors' names and affiliations, disciplinary categorization, etc.). Like every database, WoS has some limitations that are critical to consider for interpreting results (Archambault et al. 2006; Vera-Baceta et al. 2019) such as its tendency to marginalize non-English, non-internationally-oriented and low-cited research (Gingras 2002). As a result, WoS and Scopus are both dominated by English publications (in 2018, 95.37\% and 92.37\%, respectively; Vera-Baceta et al. 2019) and are both biased in terms of countries (i.e. overrepresentation of the US and of countries of main publishers) and disciplines (i.e. underrepresentation of social sciences), even though some efforts have been made to reduce these biases since the 90s (Mongeon and Paul-Hus 2016; Zhu and Liu 2020). Notwithstanding these limitations, WoS offers a good coverage of papers in natural sciences, and particularly in ecology, which are mainly published in English and are marginally impacted by aforementioned biases (Archambault et al. 2006). Considering the topic of this analysis, it was therefore a relevant database to work from.

In order to focus our analysis on ecological research, and consistently with similar works (Carmel et al. 2013), we restricted our search to the "Ecology" WoS subject category (WC). Relying on WC effectively allowed us to (i) delineate ecological research based on an objective definition of ecology journals, while (ii) taking into account a pluralistic range of conceptions and practices in ecology. Indeed, the WC system initially derives from a content-based approach that was further complemented with an automatic classification of an aggregated journal-journal citation matrix (Rafols and Leydesdorff 2009). Based on this scheme, each journal is commonly assigned to two or three categories. As a consequence, the 'Ecology' WC was relevant to capture the vast majority of ecological studies, either published in ecological journals or in more peripheral and interdisciplinary journals (such as conservation, agricultural, forestry or ecological economics journals).

Within this literature, we then focused on agricultural and forestry management practices, which are referred to with a variety of terms in the international literature, either generic (e.g. practices, interventions, management, etc.) or specific (e.g. fertilization, tillage/ploughing, pruning). Defining our global corpus therefore required to identify and select relevant keywords and keyword combinations in order to construct a relevant lexical query (Huang et al. 2015). To do so, we followed an iterative process: the integration of each candidate keyword was decided on the basis of an assessment of its capacity to capture references that were dealing with AF practices (for full details, see Appendix S1). 
In sum, our final search string was articulated around four blocks that allowed us to focus on: (i) references classified in ecology, (ii) dealing with agricultural and/or forestry activities and ecosystems, and (iii) interested in the topic of farming and/or forestry practices, but (iv) without the literature on freshwater systems. The block on agricultural and forestry activities and ecosystems was meant to specifically focus on production-oriented systems, avoiding to capture studies undertaken in areas with strict conservation status. This block did not include keywords referring to agricultural productions themselves (e.g. wood, crop, rice) because these captured a large number of publications that were irrelevant to our question (e.g. $59 \%$ of the additional publications captured with the "crop" keyword were irrelevant as they included exsitu, laboratory, genetic, physiology or pure modeling studies with no connection with in-situ AF practices).

The query was submitted on 20 February 2018 and identified a global corpus of 27556 records (of which 25647 were journal articles) published between 1956 and 2017.

\subsection{Scientometric analysis of the global corpus on AF practices in Ecology}

In a first step, we conducted scientometric analyses on the global corpus with two key objectives.

Our first objective was to assess to what extent prestigious journals paid attention to AF practices. To do so, we calculated for each journal the ratio between the number of publications present in the global corpus and the total number of publications during the studied period. On this basis, we then explored how these ratios evolved with journals' relative prestige within the 'Ecology' WC. To do so, we built a prestige journal ranking scale by computing the quartiles of average Journal Impact Factor (JIF), from Q1 (25\% most prestigious Ecology journals) to Q4 (the 25\% least ones). The average value of JIFs depended on the availability of data from the Journal Citation Reports (JCR): for journals indexed prior to 1997, we calculated their average JIF over the 1997-2017 period; for journals indexed after 1997, we calculated the average JIF from their first indexation year to 2017. A few journals were coded as 'unclassified' when data was missing in the JCR. Using a Chi2 test, we then compared the observed article distribution within the different quartiles to the expected distribution.

Our second objective was to investigate how the attention given to the topic of AF practices by ecology has changed over time. To do so, we analyzed the evolution in the yearly proportion 
of articles about this topic, taking into account the evolution of yearly JIF value and the distribution of publications per JIF quartiles through time.

\subsection{Selection of the literature subcorpus and data hand-coding}

In a second step, we conducted a qualitative content analysis of the literature (Krippendorff 2004). Due to the large size of the global corpus, we first selected a subcorpus by narrowing the analysis to articles with a minimal audience, i.e. at least 0.1 citations per year since publication ( $88.5 \%$ of the global corpus). We then applied a stratified random sampling to grant an unbiased subcorpus for two key variables: 'publication year' and 'journal'. A Chi2 test was processed to confirm that the distributions of our sample and of the global corpus were not statistically different for the 'publication year' $($ chi $2=30.8$, freedom degree $=55, p$-value $=0.996$ ) and 'journal' variables (chi2 $=195$, freedom degree $=555$ and $p$-value $=1$ ).

The resulting subcorpus consisted of 344 articles (i.e. $1.25 \%$ of the global corpus and $1.41 \%$ of articles with at least 0.1 citations per year), a size that resulted from a trade-off between statistical requirements (i.e. representativeness, robustness, generalization), the capacity of our team of 8 authors to read and hand-code the full texts of articles and the coding effort required (see below).

To analyze article content, we collaboratively built a coding scheme with the aim of extracting relevant information to explore our research questions. We tested a first version of the scheme with a subset of 15 articles, and designed a final two-level scheme organized around six types of variables, 30 variables and 83 modalities, plus article's metadata (Tables S2 and S3).

At the first level, we recorded (i) metadata about the article (e.g. journal name, year of publication, digital object identifier [DOI]), (ii) variables about the study (e.g. approach, type of system investigated, spatial extent, geographical region), (iii) whether any AF practice was mentioned in the abstract; and (iv) whether any ecological response was mentioned in the abstract. On this basis, we assessed the capacity of the lexical query to capture articles relevant to our purpose, i.e. articles dealing with terrestrial productive systems and mentioning AF practices in their title, abstract and/or keywords section. Of the 344 articles in the subcorpus, $296(86 \%)$ were coded as relevant (Fig. 1), confirming the quality of the query. Within these relevant articles, we calculated the proportion of articles that only mentioned AF practices as a contextual element or a research perspective, but did not study their effect on ecosystems. In 
total, we identified 182 articles that in fact studied the effect of AF practices on ecological variables.

For these 182 articles that made up our 'final subcorpus' (Fig. 1), we extracted two supplementary groups of variables (i.e. second-level of our coding scheme, see Table S3). First, we recorded variables about the AF practices investigated, i.e. nature, method used, type of variables and indicators used, organizational level, and how the article refers to the practitioner (e.g. mentioned or not). To aid analysis and the presentation of the results, we grouped all recorded AF practices into 27 types and 6 larger categories (crop, soil, pasture, farm, landscape, and forest-related management practices; Table S4). Second, we recorded variables about ecological responses investigated (e.g. ecological functions considered, number of parameters measured, groups of taxa considered, temporal dynamics). Ecological responses were also grouped into 16 types of ecosystem services (ES) and three ES categories (i.e. provisioning, regulating and cultural; Table S5).

Finally, to assess the reliability of the collective coding process, we equally divided the subcorpus between the 8 coauthors: each read 50 articles, including 7 articles that were read and hand-coded by another co-author. This overlap allowed us to calculate the percentage of agreement between coders, which showed good convergence for tested variables (Table S6).

\subsection{Statistical analysis of hand-coded variables}

We statistically analyzed the data collected from the final subcorpus of 182 articles in $\mathrm{R}(\mathrm{R}$ Core Team 2018). To explore the geographical and thematic focus of the selected articles as well as the nature of investigated practices, we plotted descriptive statistics using the 'ggplot2' R package for basic plots (Wickham 2016) and 'ggalluvial' for Sankey diagrams (Brunson 2019). To analyze variability between articles and create a typology, we computed Multiple Correspondence Analyses (MCA) and Hierarchical Clustering on Principal Components (HCPC) with the 'FactoMineR' R package (Lê et al. 2008). For the MCAs, we kept 11 active variables (i.e. the 6 variables characterizing AF practices and the 5 variables characterizing 'Ecological responses' of the level 2 coding scheme, Table S3), and included 'Study type' variables (level 1 of the coding scheme, Table S2) as qualitative supplementary variables. A first MCA and HCPC identified review articles as very specific compared with research articles (Fig. S1). To further explore variability within research articles, we excluded review articles 
(i.e. leaving a total of 166 articles) and processed a second MCA/HCPC analysis (Appendix S1).

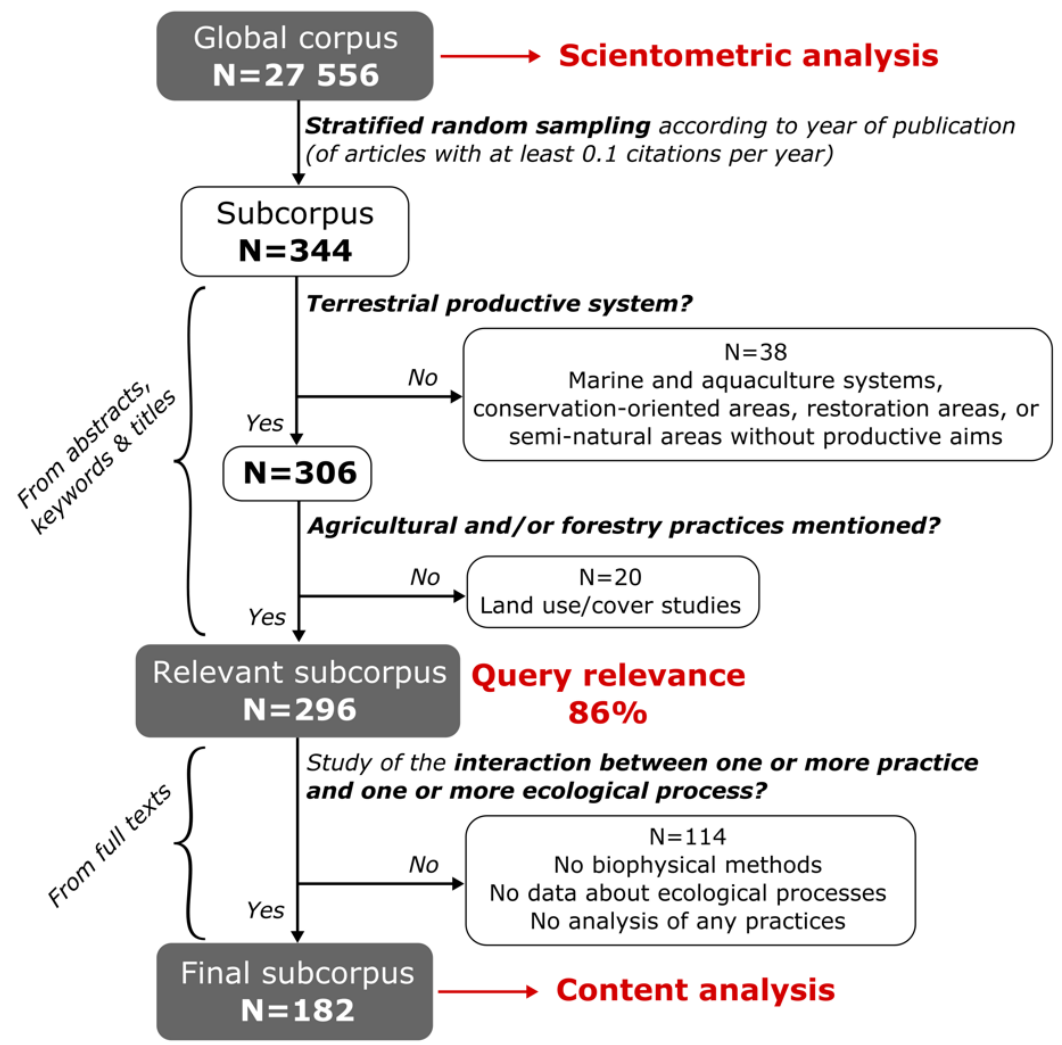

Figure 1: Selection of the relevant ecology literature and the analytical procedure. The global corpus, identified with the standardized query, was analyzed through scientometric methods. The subcorpus, established from stratified random sampling, was analyzed through content analysis to assess the relevance of the query and to extract information from the abstracts and full texts of articles. 


\section{Results}

\subsection{AF practices: a marginal, yet expanding, research topic in ecology}

Our analysis found that AF practices appeared in 5.5\% of articles published between 1956 and 2017 in the 'Ecology' category of the WoS. Half of the articles dealing with AF practices (global corpus, $N=25,647$ articles) were published in 15 journals, with the most contributions in Agriculture, Ecosystems and Environment (14.0\% of the global corpus), Journal of Applied Ecology (4.0\%) and Biological Conservation (3.9\%; Table S7). The proportion of articles dealing with AF practices varied greatly among the 15 journals: the three most contributing journals respectively represented $56.7 \%, 18.8 \%$, and $12.7 \%$ of articles dealing with such practices (Fig. 2a and Table S7).
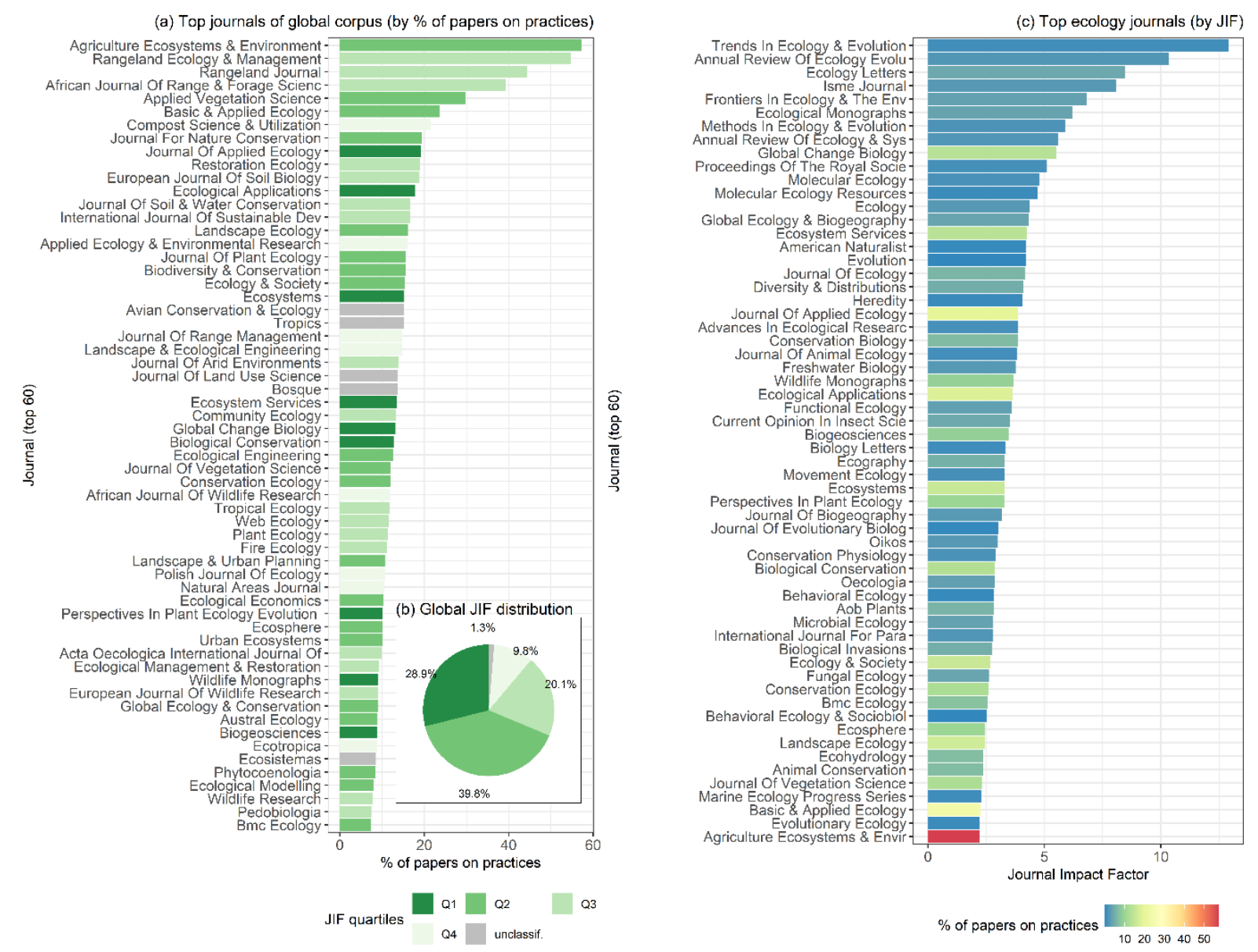

Figure 2: Evidence of the marginality of AF practices in ecology articles. (a) Top journals contributing to the global ecology corpus, showing the proportion of articles dealing with AF practices. (b) Proportion of articles within each prestige rank based on the Journal Impact Factor (JIF) quartiles (note that each quartile contains a similar proportion of journals, 25\%, but may 
contain various proportions of articles since the number of article per journal is not homogeneous - it is therefore erroneous to consider the $25 \%$ threshold as a reference to evaluate over or underrepresentation). (c) Proportion of articles dealing with AF practices in the most prestigious ecology journals.

We found that $59.9 \%$ of articles dealing with AF practices were published in journals with intermediate position in the prestige scale (i.e. in Q2 and Q3 of JIF, Fig. 2b), while 28.9\% were published in journals in the first JIF quartile. The observed distribution of articles in the different quartiles significantly differed from their expected distribution (chi2=1961.3, $\mathrm{p}<0.001)$ : articles about AF practices were under-represented in Q1 journals and overrepresented in Q2 and Q3 journals (Table S8). Journals with the highest proportion of articles dealing with AF practices tended to be specialized in human-modified ecosystems (e.g. Agriculture, Ecosystems and Environment, Rangeland Ecology and Management) or in applied ecology (e.g. Applied Vegetation Science, Basic and Applied Ecology), in contrast with generalist or theory-oriented journals (Fig. 2a). The most prestigious journals paid less attention to AF practices (Fig. 2c). For instance, the three most prestigious journals - Trends in Ecology and Evolution (TREE), Annual Review of Ecology, Evolution and Systematics (AREES), and Ecology Letters - respectively dedicated $0.84 \%, 0 \%$, and $4.2 \%$ of their articles to AF practices, and thus had low contributions to the global corpus $(0.15 \%, 0 \%$, and $0.44 \%$, respectively).

However, the proportion of articles on AF practices increased from $2.5 \%$ to $8.1 \%$ between 1991 and 2017 (Fig. 3a). The contribution of prestigious journals to the topic also increased (Fig. 3b) due to (i) the increasing number of articles published in journals with a high JIF, and (ii) the improved ranking of several journals publishing articles on practices, in particular Agriculture, Ecosystems and Environment, which progressed from Q3 to Q1 between 1997 and 2017. 
(a) Evolution of articles on practices in Ecology

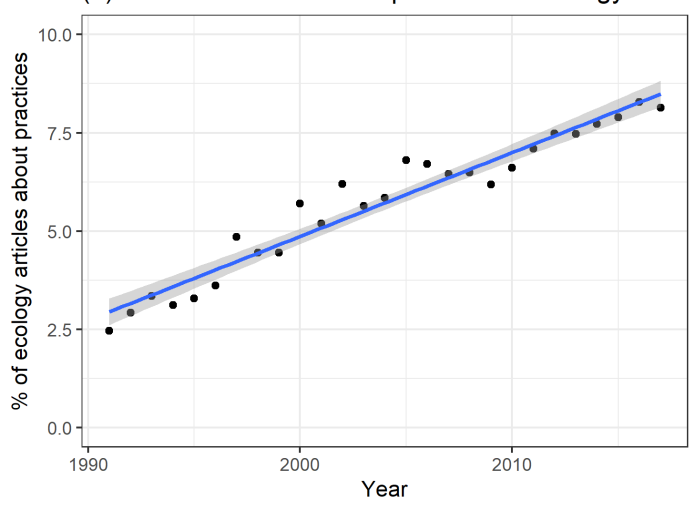

(b) Evolution of the article distribution over JIF quartiles

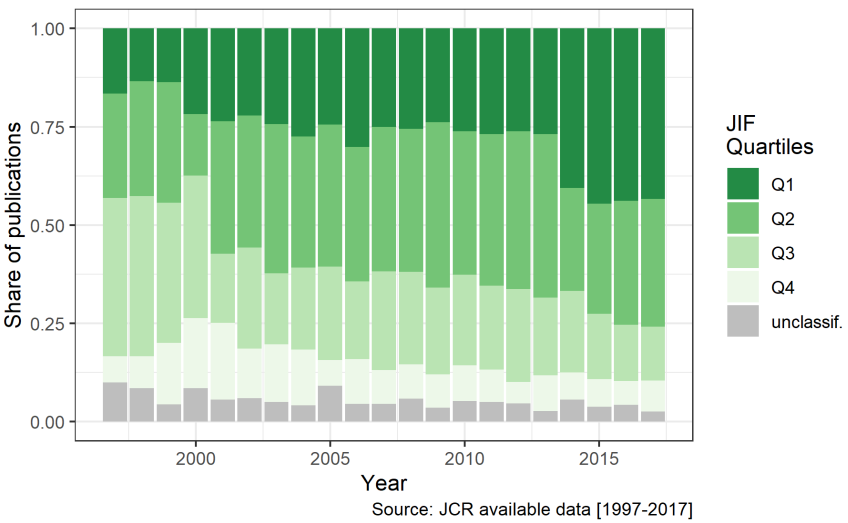

Figure 3: Temporal evolution of articles dealing with AF practices in the WoS category of 'Ecology' (the global corpus). (a) Change over time in the proportion of ecology articles on AF practices between 1990 and 2017 (fitted with a linear regression). (b) Change over time of the distribution of publications per JIF quartiles between 1997 and 2017.

\subsection{Uneven geographic and thematic consideration of AF practices}

The content analysis of the subcorpus ( $N=344$ articles) showed that only $61.5 \%$ of articles (hereafter referred to as 'final subcorpus', $N=182$ articles) effectively studied the relationship between AF practices and ecological parameters (Fig. 1). The other articles (38.5\%) only mentioned AF practices as a context, either in the introduction or conclusion of the abstract, without actually studying these.

Most articles in the final subcorpus investigated study sites located in Europe (35.7\%) or North America (33.0\%; Fig. 4a). Only two articles focused on North Africa or the Middle East. The majority of the articles focused on pastoral systems and grasslands (35.2\%) or on cropping systems (29.7\%), and provided an analysis at plot (40.7\%) or landscape level (35.7\%; Fig. 4b). 
(a)

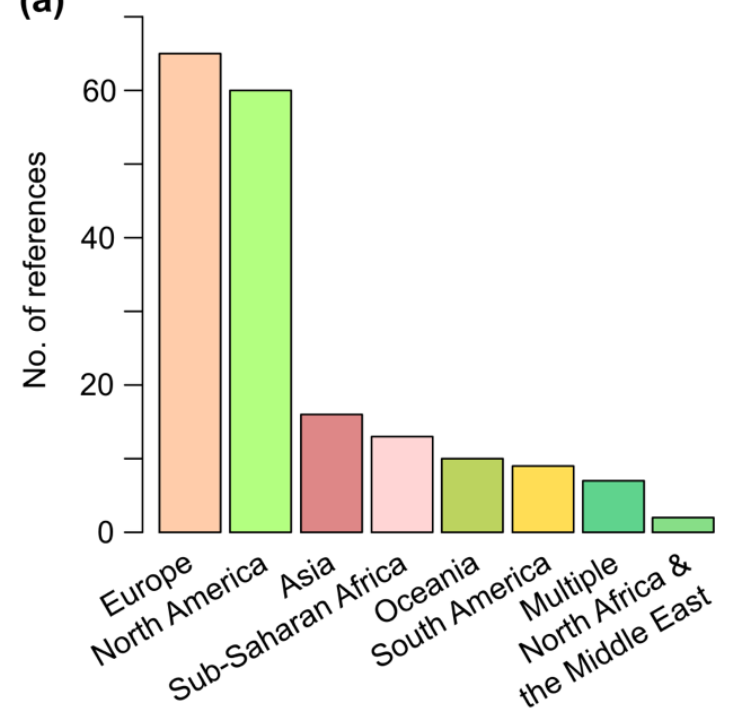

(b)

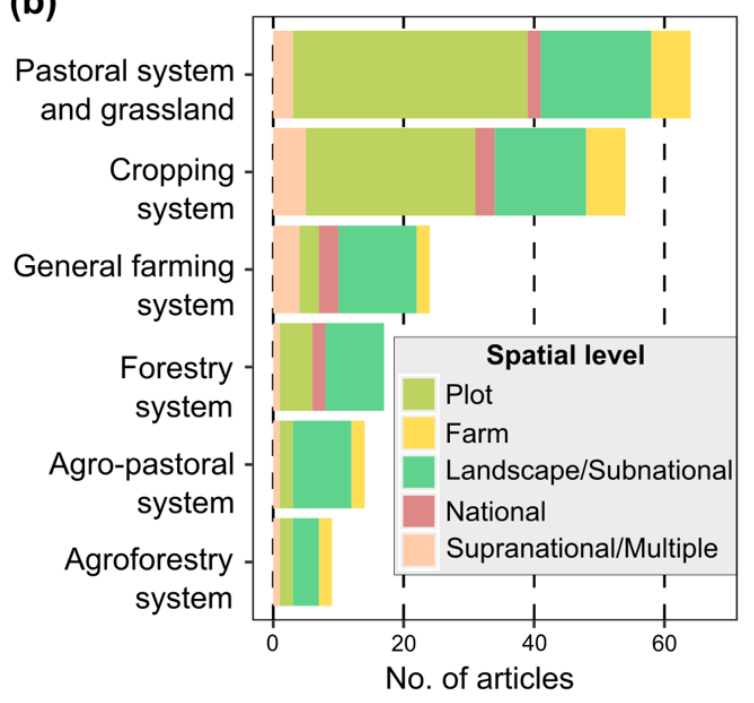

Figure 4: Geographical distribution of research on AF practices and types of productive system considered based on the 182 articles of the final subcorpus. (a) Location of study sites in the 7 main geographical regions. (b) Type of productive system investigated and the spatial level of analysis.

Within the final subcorpus, articles investigated 1.35 AF practices on average (standard deviation: $\pm 0.82 \mathrm{SD})$, with 56 articles $(30.8 \%)$ investigating more than one practice. As a result, we recorded 245 analyses of AF practices (Fig. 5 and Table S4). 'Pasture and livestock management' was the most studied category (27.3\%), encompassing studies of grazing practices (10.2\%; e.g. Kuiper and Parker 2013), pasture management (8.2\%; e.g. Hufford and Mazer 2012) or, more specifically, the intensification of grazing practices (4.9\%; e.g. Allred et al. 2012). 'Crop management' (24.9\%) was the second most represented category, and included crop selection and diversification practices $(6.5 \%)$, chemical crop pest regulation $(5.7 \%)$, and the intensification of cropping practices (2.4\%). Although 'soil' and 'landscape management' categories were less represented (respectively $19.6 \%$ and $14.7 \%$ ), they encompassed frequently investigated practices, including land use and land use changes (9.8\%; e.g. Van Meerbeek et al. 2014) and chemical soil fertility management (9.4\%). The least investigated AF practices were related to biological pest control (0.4\%; e.g. Buckley et al. 2004), to cropping schedules $(0.8 \%)$, and to the intensification of farming and forest practices (for each, 0.8\%; e.g. Kyllmar et al. 2006). 


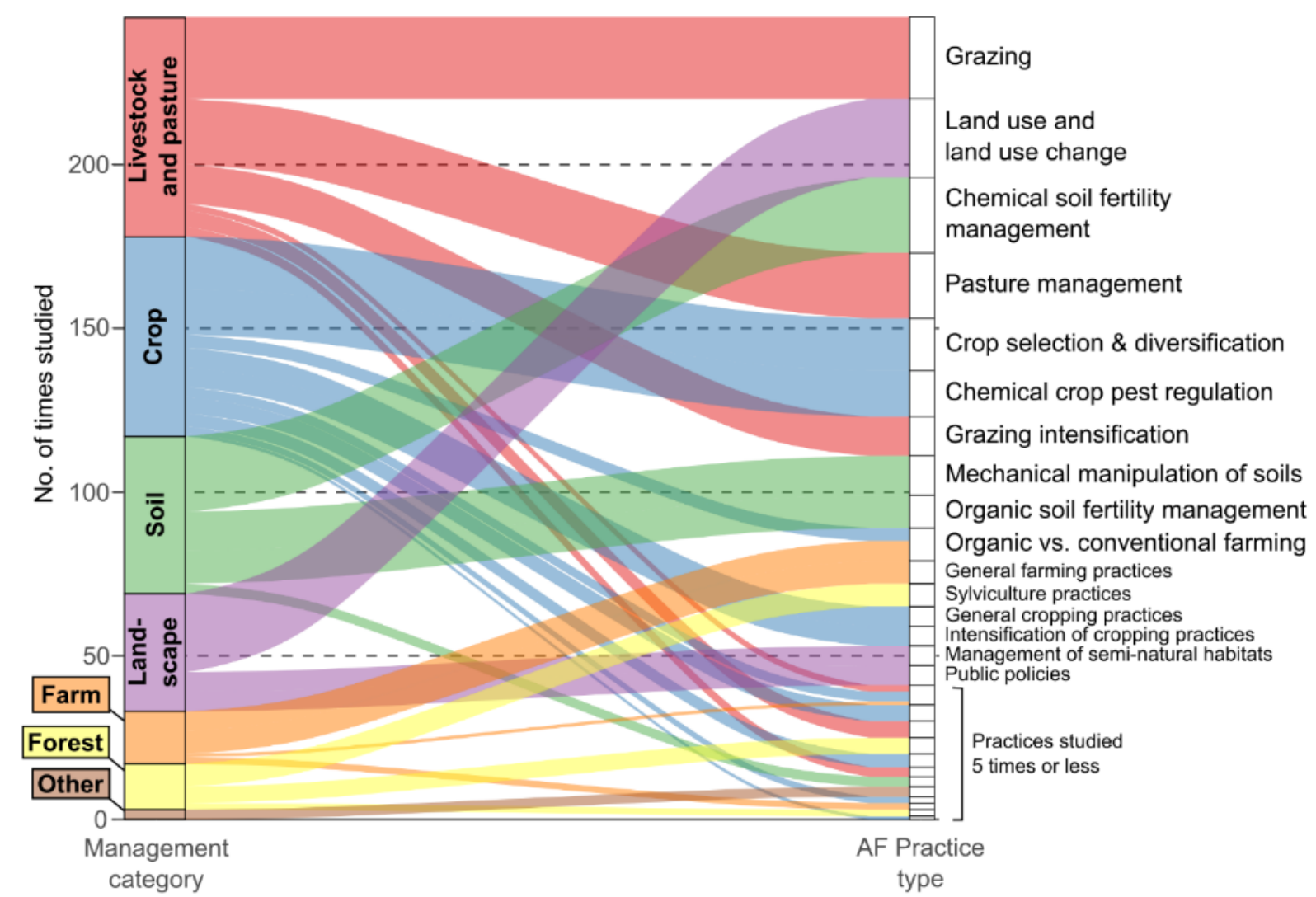

Figure 5: Overview of AF practices that were the objects of study in the final subcorpus of 182 articles, classified into 6 management categories and 27 different types (see Table S4).

\subsection{Dominance of snapshot experimental approaches at plot level}

Our analysis indicated that studies primarily used experimental approaches $(41.8 \%)$ or, to a lesser extent, indirect measurement methods (15.9\%) or direct observations of AF practices (9.9\%; Fig. 6a). A majority conducted analyses at plot level (62.6\%), whereas management units (19.8\%) and landscape level (14.3\%) were far less represented (Fig. 6c).

AF practices were generally characterized through categorical variables (35.7\%), i.e. based on different qualitative modalities of a given practice (e.g. Moisey et al. 2006), or Boolean variables (30.8\%), i.e. presence/absence of a practice (e.g. Cummings et al. 2011); Fig. 6b). Statistical analyses rarely integrated quantitative variables (15.9\%), although see Hein and Miller (1992).

The temporal characteristics of AF practices were rarely included in statistical analyses (14.3\%; Fig. 6d). When time was considered, it was often a categorical variable used to explore a season/period or year effect on an ecological response or to understand long-term responses to an AF practice (e.g. Wagoner et al. 2013). 
Lastly, 85 articles (i.e. $46.7 \%$ of them) did not consider actual practitioners. When they did, articles mainly simply mentioned the type of practitioner (e.g. Bardat and Aubert 2007). Articles taking into account farmers' behavior and values were even rarer (e.g. Jackson et al. 2007). Only 34 articles (18.7\%) provided information about who usually implements (or would implement) the studied practice (Fig. 6e).

(a) Methods

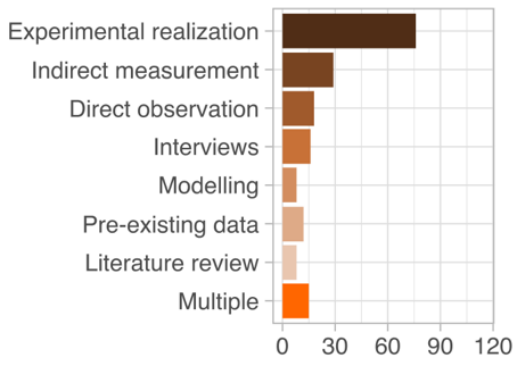

(d) Temporal aspects

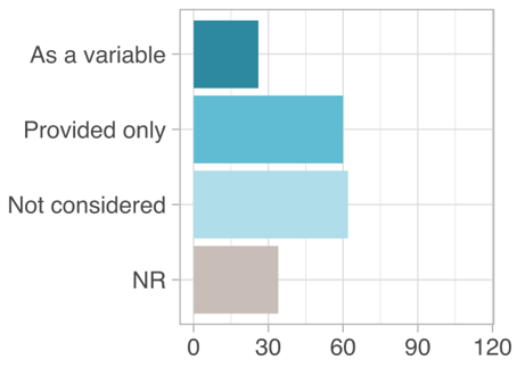

(b) Nature of variables

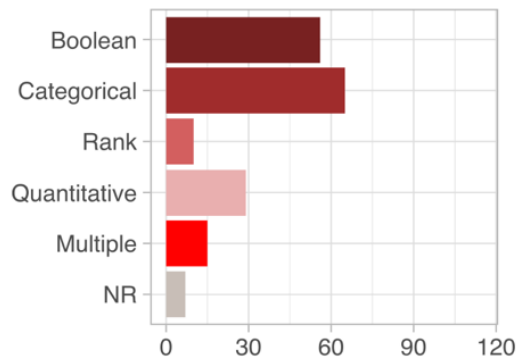

(e) Practitioners

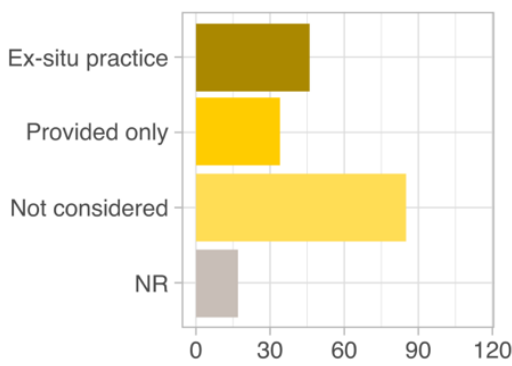

(c) Spatial level of analysis

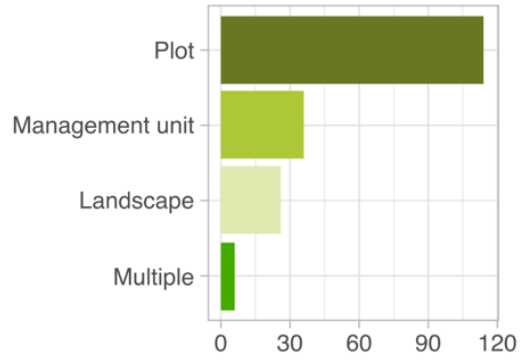

Figure 6: Overview of how AF practices were investigated in the final subcorpus $(\mathrm{N}=182$ articles). Barplots indicate the number of articles according to: (a) the methods used to collect data about practices; (b) the nature of variables used in the analyses to characterize practices; (c) the spatial level of analysis; (d) the consideration of temporal aspects; and (e) the consideration of actual practitioners. 'NR' means 'Not relevant' and was used when the nature of the investigated practice made the variable not relevant.

\subsection{Four main approaches to studying AF practices}

The multivariate analyses and clustering methods conducted on the final subcorpus identified four clusters (Table S9): one cluster of 16 review articles that was isolated from research articles (Fig. S1) and three clusters exclusively composed of 166 research articles (Fig. 7). The first axis of the MCA was mainly structured by the type of method used to collect data about AF practices (variable 'P_Methods'; eta2=0.62) and the level of analyses (variable 'P_scale'; eta2=0.54). The first axis tended to discriminate experimental studies conducted at plot level (on the left side of the graph) from studies investigating AF practices through indirect measurement and at landscape level (right side; Fig. 7b). The second axis was mainly structured 
by the type of ecological responses (variable ' $R$ _Type'; eta $2=0.50$ ) and the number of ecological responses considered (variable 'Ecol_Resp_nb_cat'; eta2=0.30).

(a) Plot of research articles and clustering

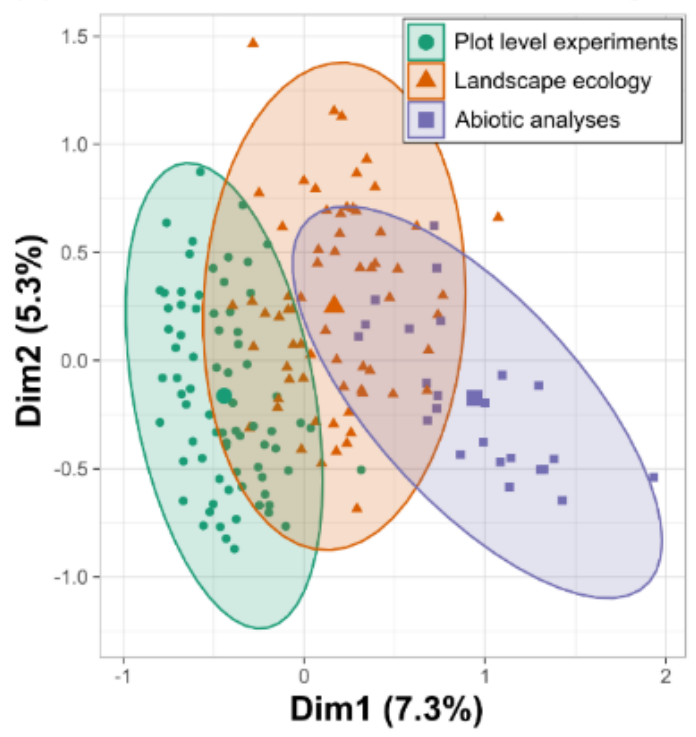

(b) Plot of active variable categories

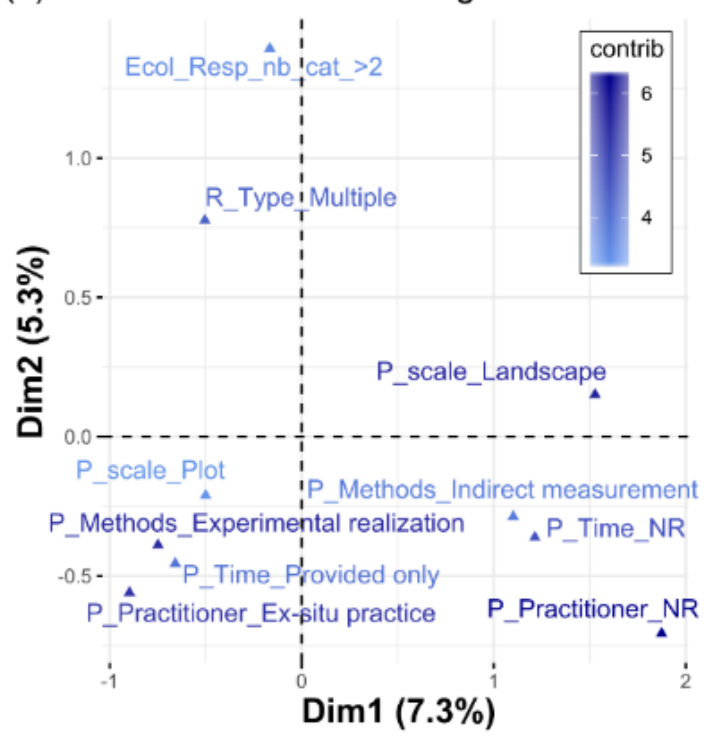

Figure 7: Multiple Correspondence Analysis (MCA) and Hierarchical Clustering on Principal Components (HCPC) performed on the 166 research articles of the final subcorpus. (a) Plot of the 166 articles in the first two axes of the MCA, regrouped in three clusters by the HCPC. (b) Plot of the active variable categories, colored according to their contribution (only the 10 most contributing categories are represented).

The 'Reviews' cluster $(N=16)$ contained reviews undertaken at international or regional levels and focusing on multiple geographical regions. For instance, McLaughlin and Mineau (1995) addressed the effects of a broad spectrum of agricultural practices on fauna and flora populations in several regions of Canada. In most reviews, no specific variable was used to characterize AF practices. For instance, Fynn et al. (2016) proposed strategic planning and management of livestock grazing in African savannas in a very qualitative manner without using precise variables. Different spatial levels were generally considered simultaneously, such as in the review by Prober and Smith (2009) that compiled 30 years of research on the Western Australian wheat belt.

The 'Plot level experiments' cluster ( $N=76$ articles; Fig. 7) mainly contained plot-level experimental studies, focusing on one single geographical region (e.g. Wagoner et al. 2013) and several ecological responses (e.g. Lees et al. 2016). AF practices were studied ex situ and temporal aspects were only mentioned and not included in the analysis (although see Smart et 
al. 2012). In this cluster, pastoral systems and grasslands were overrepresented, as well as study sites located in North America.

The 'Landscape ecology' cluster $(N=66)$ mainly contained studies at management unit level and based on direct observations or interviews. Practitioners were either not considered at all or simply mentioned for information. This cluster was characterized by the absence of temporal monitoring of ecological responses (e.g. Kyllmar et al. 2006), and by studies conducted in Europe and investigating general farming systems through a landscape-level approach (e.g. Costa et al. 2013).

The 'Abiotic analyses' cluster $(N=40)$ was mainly characterized by how ecological responses were investigated. Most of these studies (65\%) did not consider any biological taxon, but rather focused on abiotic processes such as soil mineralization without considering the biological organisms involved (e.g. Cotching and Kidd 2010). They typically focused on cropping systems and characterized AF practices through indirect measurement methods.

\section{Discussion}

\subsection{Key lessons and main limitations of this literature analysis}

This global analysis of ecology literature dealing with AF practices allowed us to reach three major conclusions about the current state of research in this topic.

First, we found that AF practices are a marginal topic in ecology, as evidenced by the low proportion of articles dealing with this and the low attention paid to the topic within the most prestigious ecology journals. However, we also found increasing attention to AF practices between 1956 and 2017, which echoes the study conducted by Carmel et al. (2013) who highlighted that the proportion of problem-solving ecological studies grew from $9 \%$ to $20 \%$ between the 1980s and the 2000s. Lowe et al. (2009) also found a similar trend toward more solution-oriented studies in applied ecology, and a greater concern for the human aspect in ecology. Nonetheless, the current proportion of ecology articles dealing with AF practices remains low $(8.1 \%)$, especially considering that our analysis focused on human-dominated ecosystems in which practices are a key driver. As every literature analysis, we are aware that our results are influenced by the database we used (WoS database and its 'Ecology' WoS 
category) and the combination of keywords that composed our search string (in particular with the need to navigate between keyword genericity and specificity). However, our methodological choices allowed to reduce such biases as much as possible and the information provided in this article ensures repeatability.

Second, we found that the majority of research on AF practices focuses on plot level and greatly relies on experimental approaches and indirect observation. Articles poorly investigate the temporal dynamics of AF practices, although this determines how current conditions came about, how ecosystems function, and how they might benefit from long-term ecological conservation and restoration planning (Davies et al. 2014). The proportion of experimental studies we found (41\%) is close to the $36 \%$ found by Carmel et al. (2013) who focused on ecological research in general and over three decades. In contrast, the proportions of observational studies $-9.9 \%$ and $45 \%$, respectively - greatly differ between our study and the one conducted by Carmel and colleagues. This difference could first be explained by differences in the literature targeted by the two studies and our focus on human-dominated ecosystems. It is also probably linked to differences in the way studies were classified: Carmel et al. (2013) classified studies as either experiments or observations, whereas we used a total of 8 categories (including interviews, indirect measurements, etc., see Fig. 6a). As we experienced in our research team, different readers might also have different interpretations for the same article (Table S6), which is a limitation that concerns all qualitative literature analyses. Finally, this difference might also come from the small size of our final subcorpus that might not be large enough to be representative of the global corpus. This limitation must yet not be overestimated considering that our results appeared relatively stable to sensitivity analyses based on a reduction of the sampling effort (see Appendix S3).

Finally, few studies were found to take into consideration the social context of AF practices, such as the characteristics and motivations of practitioners or the social and economic constraints and opportunities that drive AF practices. Even though this result could be partly explained by the underrepresentation of social sciences in international literature databases such as WoS and Scopus (Vera-Baceta et al. 2019), we think it also reflects a lack of interdisciplinary efforts to investigate AF practices and their multiple social and ecological causes and consequences. 


\subsection{Reinforcing and prioritizing research on AF practices}

These results emphasize that AF practices are a marginal topic in the ecology of humandominated systems. Some $40 \%$ of the articles captured by our lexical query only mentioned AF practices without studying their effect on ecosystems. While $5.5 \%$ of the ecology literature we identified mentioned such practices, our results suggest that only around $3.4 \%$ effectively investigated the relationships between AF practices and ecosystems. This research gap is likely to undermine the ability of ecology science to propose relevant policy recommendations for sustainability, which argues for a reinforcement of the consideration of AF practices by ecologists.

Our analyses show that AF practices were addressed by very few ecology journals, most of which emphasize applied ecology research, and are rarely considered by more generalist ecology journals. This is probably a result of the lack of scientific interaction between the different subfields of ecology (Staples et al. 2019). A first step toward increasing research on AF practices could be achieved through a better consideration of this topic by generalist ecology journals. Yet, this would surely require an effort from researchers working on AF practices regarding the genericity and upscaling of their results, which is not always feasible due to context-dependent factors. Ultimately, basic and applied ecological research, which are equally important in our present world, should be equally recognized and valued, which is currently not the case if we consider the impact factors of basic vs. applied ecological journals. At least, the evaluation of scientists should therefore take this difference into account to not disadvantage applied ecologists compared to basic ones.

We also found an overrepresentation of Europe and North America in the case studies investigated, which reflects the current concentration of research capacities and academic production in North America and Europe (Collyer 2018). Yet the current expansion of humanmodified ecosystems, in particular agricultural and managed forestry systems, mainly occurs in non-Western countries that harbor the highest levels of biodiversity worldwide (IPBES 2019). There is thus a pressing need for ecologists to also investigate non-Western areas to gain a better understanding of and to influence the ongoing major transformations that are threatening worldwide biodiversity and ecosystems.

Finally, our analysis revealed that most research into AF practices focused on cropping and pastoral systems (64.8\%), whereas more complex and diversified systems such as agro-pastoral and agroforestry systems represented less than $13 \%$ of the literature. In comparison, agricultural areas with tree cover of more than $10 \%$ represent around $45 \%$ of the total agricultural area in 
North America and Europe (Zomer et al. 2014). This gap might have two non-exclusive explanations. First, it may be due to a gap between research efforts that concentrate on monofunctional agricultural systems and real-world situations that offer a larger variety of complex agroecosystems. Second, it may be caused by a scale mismatch as research tends to focus on plot scale, and thus on a monofunctional sub-unit of management, whereas complex agroecosystems might be best captured by farm- and landscape-level approaches (Pelosi et al. 2010). In both cases, filling this gap would seem a key priority for future research in order to better support the development of agroecology from the plot to the landscape level, and to reconcile food production with biodiversity conservation challenges (Altieri 2002).

\subsection{Toward a multilevel and dynamic understanding of AF practices}

This literature analysis revealed that AF practices are mostly investigated at one single spatial level, in particular plot level, which represents $63 \%$ of the research. In contrast, landscape and multilevel analyses are poorly represented, except in review articles that summarize studies conducted at different spatial levels. Furthermore, AF practices are rarely studied through a dynamic lens, which would require time series and chronosequences.

This research gap is particularly urgent to address, as the drivers of ecological systems are known to be hierarchically organized in space and time (Wu and David 2002). For example, agricultural and forestry practices influence crop field and forest biodiversity at plot level, but also shape landscape heterogeneity and complexity in the longer term (Vasseur et al. 2013). These two nested levels are considered critical to many biodiversity and ecological processes such as resource complementation, spillovers and source-sink dynamics (Benton et al. 2003). As a consequence, further investigating the spatial and temporal configuration of AF practices in a multilevel perspective is a key research priority to better characterize the spatial mosaic and its subsequent consequences on the availability of resources for fauna and flora (Fahrig et al. 2011; Vasseur et al. 2013) and the human-induced disturbances that affect species survival.

In addition to the importance of focusing on the multiple organization levels that are relevant to the ecological system, reinforcing research efforts at levels pertinent to practitioners and social systems - such as management units, fields and farms, agrifood chains or territories - is essential to produce actionable knowledge of the interdependences between social and ecological systems (Vanloqueren and Baret 2008; Meynard et al. 2018; Ollivier et al. 2018). 


\subsection{Toward more interdisciplinary and participatory research}

Another key finding of this study is that AF practices are mostly investigated in ecology through experimental studies, whereas in vivo observations and interviews are underused. We also found that AF practices are often roughly described through Boolean or categorical variables (in $66.5 \%$ of the articles), and that the practitioners and other relevant actors are generally ignored, as well as the social or management context in which AF practices are implemented.

These findings reflect the history of ecology as a discipline. Although some major ecologists (e.g. Haeckel, Clements, Odum) have argued that ecology should be a holistic science, early on it was dominated by a reductionist epistemology and research practices meant to solidify its credibility (Hagen 1984). Experimental and statistical methods are thus mainly used to test hypotheses, and in particular to investigate causal links. This might explain why the more qualitative methods used in social sciences or natural history are disregarded in ecology, even though reproducibility issues are also critical with quantitative methods commonly used in ecology, due to a high degree of historically based, context-specific contingency (Cassey and Blackburn 2006). As a consequence, ecology is limited in its ability to consider human practitioners and their practices per se, and has a tendency to oversimplify a complex reality to fit with reproducibility and other statistical requirements. Yet while removing practitioners (and their subjectivity) from observations strengthens objectivity, it weakens the ability to put forward relevant policy recommendations because it limits understanding of why people do what they do, and what they could or should do differently. The accepted protocols and methods in ecology to establish 'proof' therefore limits ecologists' ability to take into account temporality and variability in AF practices, which are often due to practitioner characteristics or external drivers.

Many studies have highlighted the importance of better understanding the justifications, rationales and constraints - cultural, social, psychological, economic or technical - that shape practices (Mathevet et al. 2014; Ollivier et al. 2018). This better understanding is a sine qua non condition to avoid inadequate, impractical, or even stigmatizing policy recommendations, and thus to design more sustainable and effective transition pathways (Mathevet et al. 2014) as well as a more sustainable and just future (Martín-López et al. 2020).

To overcome these limitations and produce a more accurate assessment of AF practices, ecology should collaborate with fields in the social sciences and acknowledge the potential and validity of their protocols and methods (Martin 2020). For example, questionnaires and semi- 
structured interviews offer opportunities to assess people's perceptions and attitudes toward their environment, and to identify the key drivers of their practices, as has been shown by several studies in conservation biology and landscape ecology (Shova and Hubacek 2011; Dickman et al. 2014; Da Ponte et al. 2017). The relevance of such social survey tools lies in their compatibility with quantitative and multivariate analyses, offering a pathway to improve the integration of social and ecological data (Phillipson et al. 2009). Given that quantitative and statistical approaches cannot capture certain social realities, which require more in-depth and qualitative research strategies, working toward integrating these realities requires strengthening interdisciplinary research (Ollivier et al. 2018).

Another promising approach is participatory research, which allows fruitful dialogues between practitioners and scientists about opportunities for and barriers to sustainable AF practices, as well as about the desired future and how to attain it (Voinov and Bousquet 2010). While there is increasing interest in participatory approaches in ecology (Calheiros et al. 2000; Hirsch et al. 2010), our results, corroborating previous studies (Lowe et al. 2009), suggest that they remain poorly applied, perhaps because they are perceived as incompatible with ecology research practices. Working with stakeholders can pose challenges - and some ecologists may not feel skilled in this or interested in working with them - but making this effort can be highly beneficial to enrich scientific understanding, assist in ecological assessments and monitoring, and ultimately to foster relevant policy recommendations for sustainability (Mathevet et al. 2014; McElwee et al. 2020).

\section{Conclusion}

This comprehensive analysis of ecology literature focusing on the effect of agricultural and forestry management practices on ecological variables in human-dominated ecosystems showed that AF practices are a marginal, yet expanding, research topic in ecology. The findings reveal a concentration of research on European and North American case studies, with critical geographical gaps in regions where the intensification of agricultural production is currently occurring. The studies to date are also dominated by plot-level experimental studies and do not consider local practitioners or the social context that underlies their practices. To address these issues, we recommend reinforcing and improving ecology-based research on AF practices in human-dominated ecosystems. We argue that a more holistic understanding of AF practices, 
including their determinants and impacts, would benefit from more interdisciplinary collaborations and participatory research, with the ultimate goal of proposing policies that are relevant and realistic ways to achieve sustainability.

\section{References}

Allred, B. W., S. D. Fuhlendorf, F. E. Smeins, and C. A. Taylor. 2012. Herbivore species and grazing intensity regulate community composition and an encroaching woody plant in semi-arid rangeland. Basic and Applied Ecology 13: 149-158. doi:10.1016/j.baae.2012.02.007.

Altieri, M. A. 2002. Agroecology: The science of natural resource management for poor farmers in marginal environments. Agriculture, Ecosystems and Environment 93: 1-24. doi:10.1016/S0167-8809(02)00085-3.

Archambault, É., É. Vignola-Gagné, G. Côté, V. Larivière, and Y. Gingrasb. 2006. Benchmarking scientific output in the social sciences and humanities: The limits of existing databases. Scientometrics 68: 329-342. doi:10.1007/s11192-006-0115-z.

Bardat, J., and M. Aubert. 2007. Impact of forest management on the diversity of corticolous bryophyte assemblages in temperate forests. Biological Conservation 139: 47-66. doi:10.1016/j.biocon.2007.06.004.

Barnaud, G., and J.-C. Lefeuvre. 1992. L'écologie, avec ou sans l'homme. In Sciences de la nature, Sciences de la société. Les passeurs de frontières, ed. M. Jollivet, 69-112. Paris: CNRS Editions.

Baumgart-Getz, A., L. S. Prokopy, and K. Floress. 2012. Why farmers adopt best management practice in the United States: A meta-analysis of the adoption literature. Journal of Environmental Management 96. Elsevier Ltd: 17-25. doi:10.1016/j.jenvman.2011.10.006.

Benton, T. G., J. A. Vickery, and J. D. Wilson. 2003. Farmland biodiversity: is habitat heterogeneity the key? Trends in Ecology \& Evolution 18: 182-188. doi:10.1016/S0169-5347(03)00011-9.

Brunson, J. C. 2019. ggalluvial: Alluvial Plots in "ggplot2."

Buckley, Y. M., M. Rees, Q. Paynter, and M. Lonsdale. 2004. Modelling integrated weed management of an invasive shrub in tropical Australia. Journal of Applied Ecology 41: 547-560. doi:10.1111/j.00218901.2004.00909.x.

Calheiros, D. F., A. F. Seidl, and C. J. A. Ferreira. 2000. Participatory research methods in environmental science: local and scientific knowledge of a limnological phenomenon in the Pantanal wetland of Brazil. Journal of Applied Ecology 37: 684-696. doi:10.1046/j.1365-2664.2000.00524.x.

Carmel, Y., R. Kent, A. Bar-Massada, L. Blank, J. Liberzon, O. Nezer, G. Sapir, and R. Federman. 2013. Trends in Ecological Research during the Last Three Decades - A Systematic Review. PLoS ONE 8. doi:10.1371/journal.pone.0059813.

Cassey, P., and T. M. Blackburn. 2006. Reproducibility and Repeatability in Ecology. BioScience 56: 958959. doi:10.1641/0006-3568(2006)56[958:RARIE]2.0.CO;2.

Collyer, F. M. 2018. Global patterns in the publishing of academic knowledge: Global North, global South. Current Sociology 66: 56-73. doi:10.1177/0011392116680020.

Costa, D., H. Freitas, and J. P. Sousa. 2013. Influence of seasons and land-use practices on soil microbial activity and metabolic diversity in the "Montado ecosystem." European Journal of Soil Biology 59. Elsevier Masson SAS: 22-30. doi:10.1016/j.ejsobi.2013.08.003.

Cotching, W. E., and D. B. Kidd. 2010. Soil quality evaluation and the interaction with land use and soil order in Tasmania, Australia. Agriculture, Ecosystems \& Environment 137. Elsevier B.V.: 358-366. doi:10.1016/j.agee.2010.03.006.

Cummings, J. L., R. W. Byrd, W. R. Eddleman, R. M. Engeman, and S. K. Tupper. 2011. Effectiveness of AV$1011{ }^{\circledR}$ to reduce damage to drill-planted rice from blackbirds. The Journal of Wildlife Management 75: 353-356. 
doi:10.1002/jwmg.65.

Davies, A. L., S. Colombo, and N. Hanley. 2014. Improving the application of long-term ecology in conservation and land management. Journal of Applied Ecology 51: 63-70. doi:10.1111/1365-2664.12163.

Dessart, F. J., J. Barreiro-Hurlé, and R. Van Bavel. 2019. Behavioural factors affecting the adoption of sustainable farming practices: A policy-oriented review. European Review of Agricultural Economics 46: 417471. doi:10.1093/erae/jbz019.

Dickman, A. J., L. Hazzah, C. Carbone, and S. M. Durant. 2014. Carnivores, culture and "contagious conflict": Multiple factors influence perceived problems with carnivores in Tanzania's Ruaha landscape. Biological Conservation 178: 19-27. doi:10.1016/j.biocon.2014.07.011.

Fahrig, L., J. Baudry, L. Brotons, F. G. Burel, T. O. Crist, R. J. Fuller, C. Sirami, G. M. Siriwardena, et al. 2011. Functional landscape heterogeneity and animal biodiversity in agricultural landscapes. Ecology Letters 14 : 101-112. doi:10.1111/j.1461-0248.2010.01559.x.

Fynn, R. W. S., D. J. Augustine, M. J. S. Peel, and M. de Garine-Wichatitsky. 2016. Strategic management of livestock to improve biodiversity conservation in African savannahs: a conceptual basis for wildlife-livestock coexistence. Edited by Sarah Durant. Journal of Applied Ecology 53: 388-397. doi:10.1111/1365-2664.12591.

Gingras, Y. 2002. Les formes spécifiques de l'internationalité du champ scientifique. Actes de la recherche en sciences sociales 2: 31-45.

Guerrero, A. M., N. J. Bennett, K. A. Wilson, N. Carter, D. Gill, M. Mills, C. D. Ives, M. J. Selinske, et al. 2018. Achieving the promise of integration in social-ecological research: a review and prospectus. Ecology and Society 23: art38. doi:10.5751/ES-10232-230338.

Hagen, J. B. 1984. Experimentalists and naturalists in twentieth-century botany: Experimental taxonomy, 1920?1950. Journal of the History of Biology 17: 249-270. doi:10.1007/BF00143734.

Hein, D. G., and S. D. Miller. 1992. Influence of Leafy Spurge on Forage Utilization by Cattle. Journal of Range Management 45: 405. doi:10.2307/4003092.

Hirsch, D., G. Abrami, R. Giordano, S. Liersch, N. Matin, and M. Schlüter. 2010. Participatory Research for Adaptive Water Management in a Transition Country - a Case Study from Uzbekistan. Ecology and Society 15: art23. doi:10.5751/ES-03549-150323.

Holling, C. S. 1969. Stability in ecological and social systems. Brookhaven Symposia in biology 22: 128-141.

Holling, C. S. 1973. Resilience and stability of ecological systems. Annual Review of Ecology and Systematics 4: $1-23$.

Huang, Y., J. Schuehle, A. L. Porter, and J. Youtie. 2015. A systematic method to create search strategies for emerging technologies based on the Web of Science: illustrated for 'Big Data.' Scientometrics 105. Springer Netherlands: 2005-2022. doi:10.1007/s11192-015-1638-y.

Hufford, K. M., and S. J. Mazer. 2012. Local Adaptation and the Effects of Grazing on the Performance of Nassella pulchra: Implications for Seed Sourcing in Restoration. Restoration Ecology 20: 688-695. doi:10.1111/j.1526-100X.2011.00843.x.

IPBES. 2019. Summary for policymakers of the global assessment report on biodiversity and ecosystem services of the Intergovernmental Science-Policy Platform on Biodiversity and Ecosystem Services. Edited by S. Díaz, J. Settele, E. S. Brondízio, H. T. Ngo, M. Guèze, J. Agard, A. Arneth, P. Balvanera, et al. Bonn, Germany: IPBES Secretariat. doi:10.5281/zenodo.3553579.

Jackson, R. D., M. M. Bell, and C. Gratton. 2007. Assessing ecosystem variance at different scales to generalize about pasture management in southern Wisconsin. Agriculture, Ecosystems \& Environment 122: 471-478. doi:10.1016/j.agee.2007.03.004.

Kinchy, A. J., and D. L. Kleinman. 2003. Organizing Credibility. Social Studies of Science 33: 869-896. doi:10.1177/0306312703336003.

Krippendorff, K. 2004. Content analysis: An introduction to its methodology. Sage Publications, Inc.

Kuiper, T. R., and D. M. Parker. 2013. Grass height is the determinant of sheep grazing effects on small mammals in a savanna ecosystem. The Rangeland Journal 35: 403. doi:10.1071/RJ13063.

Kyllmar, K., C. Carlsson, A. Gustafson, B. Ulén, and H. Johnsson. 2006. Nutrient discharge from small agricultural catchments in Sweden. Agriculture, Ecosystems \& Environment 115: 15-26. 
doi:10.1016/j.agee.2005.12.004.

Lê, S., J. Josse, and F. Husson. 2008. FactoMineR: An R Package for Multivariate Analysis. Journal of Statistical Software 25. doi:10.18637/jss.v025.i01.

Lees, K. J., A. J. McKenzie, J. P. Newell Price, C. N. Critchley, C. M. Rhymer, B. J. Chambers, and M. J. Whittingham. 2016. The effects of soil compaction mitigation on below-ground fauna: How earthworms respond to mechanical loosening and power harrow cultivation. Agriculture, Ecosystems \& Environment 232. Elsevier B.V.: 273-282. doi:10.1016/j.agee.2016.07.026.

Liu, J. 2001. Integrating ecology with human demography, behavior, and socioeconomics: Needs and approaches. Ecological Modelling 140: 1-8. doi:10.1016/S0304-3800(01)00265-4.

Lopes, S. de F. 2017. The other side of Ecology: thinking about the human bias in our ecological analyses for biodiversity conservation. Ethnobiology and Conservation 6: 1-8. doi:10.15451/ec2017-08-6.14-1-24.

Loucks, O. L. 1977. Emergence of Research on Agro-Ecosystems. Annual Review of Ecology and Systematics 8: 173-192. doi:10.1146/annurev.es.08.110177.001133.

Lowe, P., G. Whitman, and J. Phillipson. 2009. Ecology and the social sciences. Journal of Applied Ecology 46: 297-305. doi:10.1111/j.1365-2664.2009.01621.x.

Madison, M. G. 1997. "Potatoes Made of Oil": Eugene and Howard Odum and the Origins and Limits of American Agroecology. Environment and History 3: 209-238.

Martin, V. Y. 2020. Four Common Problems In Environmental Social Research Undertaken by Natural Scientists. BioScience 70: 13-16. doi:10.1093/biosci/biz128.

Martín-López, B., P. Balvanera, R. Manson, T. H. Mwampamba, and A. Norström. 2020. Contributions of place-based social-ecological research to address global sustainability challenges. Global Sustainability 3: e21. doi:10.1017/sus.2020.18.

Mathevet, R., C. Vuillot, and C. Sirami. 2014. Effective Nature Conservation on Farmland: Can We Change Our Own Models, Not Just the Farmers? Conservation Letters 7: 575-576. doi:10.1111/conl.12064.

McElwee, P., Á. Fernández-Llamazares, Y. Aumeeruddy-Thomas, D. Babai, P. Bates, K. Galvin, M. Guèze, J. Liu, et al. 2020. Working with Indigenous and local knowledge (ILK) in large-scale ecological assessments: Reviewing the experience of the IPBES Global Assessment. Edited by Helen Wheeler. Journal of Applied Ecology: 1365-2664.13705. doi:10.1111/1365-2664.13705.

McLaughlin, A., and P. Mineau. 1995. The impact of agricultural practices on biodiversity. Agriculture, Ecosystems \& Environment 55: 201-212. doi:10.1016/0167-8809(95)00609-V.

Van Meerbeek, K., K. Helsen, and M. Hermy. 2014. Impact of land-use intensity on the conservation of functional and phylogenetic diversity in temperate semi-natural plant communities. Biodiversity and Conservation 23: 2259-2272. doi:10.1007/s10531-014-0720-8.

Meynard, J.-M., F. Charrier, M. Fares, M. Le Bail, M.-B. Magrini, A. Charlier, and A. Messéan. 2018. Sociotechnical lock-in hinders crop diversification in France. Agronomy for Sustainable Development 38. Agronomy for Sustainable Development: 54. doi:10.1007/s13593-018-0535-1.

Moisey, D. M., W. D. Willms, and E. W. Bork. 2006. Effect of Standing Litter on Rough Fescue Utilization by Cattle. Rangeland Ecology \& Management 59. Elsevier: 197-203. doi:10.2111/05-039R1.1.

Mongeon, P., and A. Paul-Hus. 2016. The journal coverage of Web of Science and Scopus: a comparative analysis. Scientometrics 106: 213-228. doi:10.1007/s11192-015-1765-5.

Ollivier, G., D. Magda, A. Mazé, G. Plumecocq, and C. Lamine. 2018. Agroecological transitions: What can sustainability transition frameworks teach us? An ontological and empirical analysis. Ecology and Society 23: art5. doi:10.5751/ES-09952-230205.

Pelosi, C., M. Goulard, and G. Balent. 2010. The spatial scale mismatch between ecological processes and agricultural management: Do difficulties come from underlying theoretical frameworks? Agriculture, Ecosystems and Environment 139: 455-462. doi:10.1016/j.agee.2010.09.004.

Phillipson, J., P. Lowe, and J. M. Bullock. 2009. Navigating the social sciences: interdisciplinarity and ecology. Journal of Applied Ecology 46: 261-264. doi:10.1111/j.1365-2664.2009.01625.x.

Da Ponte, E., C. Kuenzer, A. Parker, O. Rodas, N. Oppelt, and M. Fleckenstein. 2017. Forest cover loss in Paraguay and perception of ecosystem services: A case study of the Upper Parana Forest. Ecosystem Services 24. 
Elsevier B.V.: 200-212. doi:10.1016/j.ecoser.2017.03.009.

Prober, S. M., and F. P. Smith. 2009. Enhancing biodiversity persistence in intensively used agricultural landscapes: A synthesis of 30 years of research in the Western Australian wheatbelt. Agriculture, Ecosystems \& Environment 132: 173-191. doi:10.1016/j.agee.2009.04.005.

R Core Team. 2018. R: A Language and Environment for Statistical Computing. Vienna, Austria: R Foundation for Statistical Computing.

Rafols, I., and L. Leydesdorff. 2009. Content-based and algorithmic classifications of journals: Perspectives on the dynamics of scientific communication and indexer effects. Journal of the American Society for Information Science and Technology 60: 1823-1835. doi:10.1002/asi.21086.

Shova, T., and K. Hubacek. 2011. Drivers of illegal resource extraction: An analysis of Bardia National Park, Nepal. Journal of Environmental Management 92: 156-164. doi:10.1016/j.jenvman.2010.08.021.

Smart, A. J., R. N. Gates, P. S. Johnson, and R. Schafer. 2012. Summer and Winter Defoliation Impacts on Mixed-Grass Rangeland. Rangeland Ecology \& Management 65. Elsevier Masson SAS: 506-515. doi:10.2111/REM-D-11-00173.1.

Staples, T. L., J. M. Dwyer, C. E. Wainwright, and M. M. Mayfield. 2019. Applied ecological research is on the rise but connectivity barriers persist between four major subfields. Journal of Applied Ecology 56: 1492-1498. doi:10.1111/1365-2664.13373.

Steffen, W., P. J. Crutzen, and J. R. McNeill. 2007. The anthropocene: Are humans now overwhelming the great forces of nature? Ambio 36: 614-621. doi:10.1579/0044-7447(2007)36[614:TAAHNO]2.0.CO;2.

Vanloqueren, G., and P. V. Baret. 2008. Why are ecological, low-input, multi-resistant wheat cultivars slow to develop commercially? A Belgian agricultural 'lock-in' case study. Ecological Economics 66: 436-446. doi:10.1016/j.ecolecon.2007.10.007.

Vasseur, C., A. Joannon, S. Aviron, F. Burel, J.-M. Meynard, and J. Baudry. 2013. The cropping systems mosaic: How does the hidden heterogeneity of agricultural landscapes drive arthropod populations? Agriculture, Ecosystems \& Environment 166: 3-14. doi:10.1016/j.agee.2012.08.013.

Vera-Baceta, M.-A., M. Thelwall, and K. Kousha. 2019. Web of Science and Scopus language coverage. Scientometrics 121: 1803-1813. doi:10.1007/s11192-019-03264-z.

Voinov, A., and F. Bousquet. 2010. Modelling with stakeholders. Environmental Modelling \& Software 25. Elsevier Ltd: 1268-1281. doi:10.1016/j.envsoft.2010.03.007.

Wagoner, S. J., L. A. Shipley, R. C. Cook, and L. Hardesty. 2013. Spring cattle grazing and mule deer nutrition in a bluebunch wheatgrass community. The Journal of Wildlife Management 77: 897-907. doi:10.1002/jwmg.545. 4.

Wickham, H. 2016. ggplot2. Use R! Cham: Springer International Publishing. doi:10.1007/978-3-319-24277-

Worster, D. 1994. Nature's economy: a history of ecological ideas. 2nd ed. Studies in Environment and History. Cambridge ; New York, NY, USA: Cambridge University Press.

$\mathrm{Wu}$, J., and J. L. David. 2002. A spatially explicit hierarchical approach to modeling complex ecological systems: theory and applications. Ecological Modelling 153: 7-26. doi:10.1016/S0304-3800(01)00499-9.

Zhu, J., and W. Liu. 2020. A tale of two databases: the use of Web of Science and Scopus in academic papers. Scientometrics 123: 321-335. doi:10.1007/s11192-020-03387-8.

Zomer, R. J., Trabucco A, R. Coe, F. Place, M. van Noordwijk, and J. C. Xu. 2014. Trees on farms: an update and reanalysis of agroforestry's global extent and socio-ecological characteristics. doi:10.5716/WP14064.PDF. 